\title{
Evaluating the Readiness of Mobile Technology with Respect to e-Heath for Medication in Saudi Arabia: An Integrative Perspective
}

This article was published in the following Dove Press journal: Journal of Multidisciplinary Healthcare

\author{
Fahad M Al-Anezi \\ Community College, Imam Abdulrahman \\ Bin Faisal University, Dammam, Saudi \\ Arabia
}

Objective: The objective of this study was to evaluate the readiness of Saudi Arabian patients towards the adoption of the e-health system through the use of mobile phones.

Methods: In this research, a cross-sectional survey was carried out using a self-administered structured questionnaire. According to the results, 354 people viewed the questionnaire and 129 respondents were selected to assess the adoption of the e-health system in Saudi Arabia. The data were collected during February-March 2020.

Results: More than half of the respondents (63.6\%) were women and almost half of the participants (48.0\%) were married. Most of the surveyed patients suffered from cardiovascular diseases and diabetes. Almost all the participants $(99.0 \%)$ had their personal mobile phone and used the Internet on these devices. Most of the participants did not trust or believe in online health services or online medical consultations and did not spend money on contracting health services through mobile phones. It is suggested that the lack of motivation to adopt the e-health system may be due to fear of privacy violations, fear of loss of personal data and information, lack of technical support, and mistrust in doctors who frequently use their cell phones to distract themselves during work-hours.

Conclusion: The results of this study revealed that the population of Saudi Arabia is reluctant to adopt the electronic e-health system promoted in the Saudi Vision 2030 strategic plan. To change this behavior, it is necessary to develop awareness campaigns and strategies that suggest the importance of using e-heath in the Saudi Arabian healthcare system. Additionally, it is essential that the network administrator implement procedures to protect the confidentiality and security of patients' medical records.

Keywords: Saudi Arabia, mobile phones, electronic health, adoption, e-health

\section{Introduction}

In the past three decades, the express development of information and communication technology (ICT) has caused significant advancement in the healthcare area, and some studies have shown that ICT-based e-health services noticeably affect the development of the healthcare sector. ${ }^{1,2}$

It is worth mentioning that e-health is an emerging field in the intersection of medical informatics, public health, and business, referring to health services and information delivered or enhanced through the Internet and related technologies. In a broader sense, the term characterizes not only a technical development but also a state-of-mind, a way of thinking, an attitude, and a commitment for networked, global thinking, to improve health care locally, regionally, and worldwide by using
Correspondence: Fahad M Al-Anezi Community College, Imam Abdulrahman Bin Faisal University, Saudi Arabia Email fmoalanezi@iau.edu.sa
Journal of Multidisciplinary Healthcare 2021:14 59-66 
information and communication technology. ${ }^{3}$ Also, the World Health Organization (WHO) describes e-health as "the leveraging of the information and ICT to connect providers and patients and governments; to educate and inform healthcare professionals, managers, and consumers; to stimulate innovation in care delivery and health system management; and to improve our healthcare". 4 According to the WHO, the possibility that all people in the world receive high-quality health services at reasonable costs cannot be achieved without the support of e-health. ${ }^{5}$ The utilization of the ICT system certifies individual behavior, individual thinking, and individual's commitment towards the global approach of healthcare services. ${ }^{6}$ In general, e-health is related to the use of telecommunications, digital technologies, the Internet, computers, processors, smart phones, and other mobile systems, to facilitate the enhancement of healthcare services. $^{7}$

Many developed countries have invested a substantial amount of resources to continue implementing and improving e-health systems to lower their costs and to improve the quality of life. ${ }^{8}$ Recent studies show rapid progress in the utilization of electronic health system in developed countries and these countries are now increasing their wings from the existing quality of health toward the digital healthcare system. ${ }^{9}$ The digital healthcare system increases healthcare quality, affordability, accessibility, reduces cost of medical treatment, contributes to minimize medical errors, improves workflow, etc. ${ }^{10}$ Similarly, e-health improves diagnosis and treatment, reduces waiting times, and facilitates diseases prevention and care coordination. ${ }^{11}$ Though e-health has good prospects for providing improved health services and quality to people at a lower cost, its adoption and acceptance processes are not equally straightforward; in reality, understanding the acceptance or rejection of new information systems is regarded as a challenge in the field of information systems. ${ }^{12}$

Regarding Saudi Arabia, it is a diverse and fast progressing country and its GDP was $0.3 \%$ in $2019 .{ }^{13}$ Like other countries, the population of Saudi Arabia is also increasing rapidly. According to the United Nations projections, the population of Saudi Arabia in 2025 will increase by $40 \%$ compared to $2020 .^{14}$ The increase in population will increase the demand of medical health facilities. Also, out of 190 countries, Saudi Arabia healthcare system stands at 26th position, and about
2037 healthcare clinics and 244 hospitals (government and non-government) operate in this country. ${ }^{15}$ To achieve the goal of providing free health services to the citizens, Saudi Arabia delivers services via the Ministry of Health $(\mathrm{MoH})$, private health service providers, and government health service providers. ${ }^{16}$ To provide better free services, the Saudi government allocated about 4 billion (Saudi Riyal) to the health system. $^{17}$

A number of issues pose challenges to the healthcare facilities/sectors of Saudi Arabia. The most important challenge is the non-availability of professional doctors or nurses $(<0.94$ per 1000 people) regardless of spending a huge amount of resources. Moreover, lifestyle pattern and diseases, financial constraints, poor accessibility are other important challenges. Keeping these challenges in mind, the Saudi government is keen to invest in different ICTbased e-health services. ${ }^{18}$ Recent studies showed that despite huge spending on various tools like Electronic Medical Coverage (EMC), Electronic Medical Record (EMR), Electronic Health Record (EHR), Picture Archiving and Communication Systems (PACS), the government still face barriers in the adoption of the e-health systems. ${ }^{1,19}$ These barriers include cultural norms, illiteracy, inadequate knowledge of computer, and other IT skills. ${ }^{18}$

Healthcare is the priority sector in the Saudi Arabia's vision 2030 strategic plan, in which the key factor is the improvement of healthcare facilities for the residents of Saudi Arabia. ${ }^{20}$ E-health and other ICTs are core components of vision 2030. Currently, the e-health system is under progress and a previous study indicated that this system was established in Saudi Arabia in late 2008. ${ }^{21}$ Now, it is in the second phase of progress and the government spends annually between $10 \%$ and $15 \%$ of the budget on the development of the e-health system throughout the country. After this operating time, it is necessary and important to perform an e-health readiness assessment that could provide some advantages, such as: (1) avoiding huge losses in time, money, and effort; (2) avoiding delays and disappointments among planners, staff, and users of services; and (3) facilitating the process of change in the institutions and communities involved, from the stage of firmness and resistance to change to the stage of implementation of the e-health system. $^{22}$ Therefore, this study is an attempt to evaluate the readiness of patients to adopt the e-health applications in Saudi Arabia through the use of mobile phones. 


\section{Methods}

\section{Study Settings and Participants}

A cross-sectional survey was used to evaluate the individuals' attitude towards e-health readiness, and the data were collected using a self-administered structured questionnaire. In this process, a group of Saudi Arabian citizens were asked to participate on a voluntarily basis and the average time taken to complete the survey was approximately 10 minutes. Only patients from Saudi Arabia were included and full privacy of the participants was maintained during the study.

\section{Description of the Questionnaire}

The questionnaire was based on the literature review about the utilization of mobile phones among medical professionals, students, and patients for healthcare services. ${ }^{23,24}$ The questionnaire consisted of 37 validated questions and was divided into 7 sections. The first section deals with general demographic information of the respondents. The second section was related to knowledge about the overall health profile of the participants. The third section deals with awareness of the electronic health system in the region. The fourth part deals with the availability, training, and utilization of mobile phones. The fifth considers the utilization of mobile tools and applications (apps) for healthcare services. The sixth section deals with the trust of respondents on online healthcare services, and the seventh with the cost of online healthcare services. The questionnaire was initially designed in English and then was translated into Arabic by two professional Arabic translators. The Arabic version of the questionnaire was designed using the QuestionPro application.

\section{Data Collection}

A link was generated for accessing the survey and the data were collected during February-March, 2020. According to the survey results, 354 people viewed the questionnaire, and 171 of them started the survey. Forty-two respondents were removed from the survey for lack of responses. After removing them, 129 respondents were selected to access the readiness for the adoption of the e-health system in Saudi Arabia.

\section{Validation of the Questionnaire}

To evaluate the questionnaire, a pilot study was conducted with 10 randomly selected participants from the college of Business \& Marketing, Imam Abdulrahman Bin Faisal
University, Saudi Arabia. Based on the feedback from the pilot study, a few changes were made to the questions' formulation and some grammatical errors in Arabic were corrected. The responses observed in the pilot study were consistent. The Cronbach's alpha value was calculated to test the reliability of the survey. The alpha value was 0.886 . This value suggested that the questionnaire was reliable.

\section{Ethical Approach}

The study was conducted in accordance with the Declaration of Helsinki and the ethical approval was received from the Imam Abdulrahman Bin Faisal University. In addition, the participants were ensured of their privacy and anonymity to participate in the survey. The survey data were stored in the QuestionPro database, which was password protected and only accessible by researchers. In addition, the participants were fully informed about the purpose and data usage of the study, which was strictly for academic purpose. The informed consent was obtained from the participants electronically. Accordingly, all the guidelines proposed by the ethical committee of the mentioned university were followed.

\section{Statistical Analysis}

Microsoft Excel and IBM SPSS statistics were used to generate the descriptive statistics of the data and the itemlevel results of each question of the survey. In addition, Cronbach's alpha value was calculated to test the reliability of the survey. $P$-values were also calculated. A significance level of 5\% was used for the analyses.

\section{Results}

\section{Demographic Information of Respondents}

The demographic information of respondents is shown in Table 1. According to this table, a total of 129 respondents participated in the survey, and the majority of them were females $(63.6 \%, n=82)$. Also, $48.0 \%(n=62)$ of the respondents were married. The results showed that $7.6 \%(n=10)$ of the participants completed the high school diploma, $31.0 \%(n=40)$ passed out the college level studies, $48.8 \%$ $(n=63)$ of the respondents completed the graduate level education, and $12.4 \%$ (16) completed other institutional studies. The results showed that most of the respondents were job holders $(53.5 \%, \mathrm{n}=69)$; they are either businessmen or students. 
Table I Demographic Information of Respondents $(n=129)$

\begin{tabular}{|l|l|l|l|}
\hline Variables & n (\%) & Mean Value & P value \\
\hline $\begin{array}{l}\text { Gender } \\
\text { Male }\end{array}$ & $47(36.4)$ & 1.64 & \\
Female & $82(63.6)$ & & 0.0483 \\
\hline Education & & & \\
High school diploma & $10(7.6)$ & 4.65 & 0.795 \\
College & $40(31.0)$ & & \\
Degree & $63(48.8)$ & & \\
Other & $16(12.4)$ & & \\
\hline Marital status & & & \\
Married & $62(48.0)$ & 2.87 & \\
Widowed & $2(1.5)$ & & \\
Divorced & $10(7.7)$ & & \\
Separated & $2(1.5)$ & & \\
Single & $51(39.5)$ & & \\
Never married & $2(1.5)$ & & \\
\hline Occupation & & & \\
Businessman & $4(3.1)$ & 2.64 & \\
Job holder & $69(53.5)$ & & \\
Student & $25(19.4)$ & & \\
Other & $31(24.0)$ & & \\
\hline
\end{tabular}

\section{Information About the Overall Health}

\section{Profile of the Respondents}

In this survey, 2 questions were asked to know about the overall health profile of the respondents. The answers to these questions are shown in Table 2, where it is observed that the majority of the respondents $(81.2 \%, \mathrm{n}=105)$ were not taking medication. Also, most of the respondents suffered from cardiovascular diseases and diabetes.

\section{Knowledge of the Respondents About the e-Health System}

In this survey, a question was asked to find out if the participants had knowledge of the e-health system. In this regard, out of 129 participants, 79 of them (61.4\%) indicated that they had knowledge about this system.

\section{Use of Mobile Phones by the Respondents}

Table 3 describes the use of mobile phones by the respondents. This table indicates that $99.0 \%(128 / 129)$ of the respondents were using their own mobile phones. Also, $34.9 \%(45 / 129)$ of the participants received healthcare messages.
Table 2 Overall Health Profile of the Respondents $(n=129)$

\begin{tabular}{|l|l|l|l|}
\hline Variables & $\mathbf{n}(\%)$ & Mean Value & P value \\
\hline $\begin{array}{l}\text { Are you currently } \\
\text { taking any medication? } \\
\text { Yes } \\
\text { No }\end{array}$ & $\begin{array}{l}24(18.8) \\
105(81.2)\end{array}$ & 1.81 & \\
\hline $\begin{array}{l}\text { Have you been } \\
\text { diagnosed with any of } \\
\text { the following diseases? } \\
\text { Hypertension } \\
\text { Yes }\end{array}$ & $\begin{array}{l}124(96.1) \\
\text { No }\end{array}$ & 4.84 & 0.039 \\
\hline $\begin{array}{l}\text { Cardiovascular diseases } \\
\text { Yes }\end{array}$ & $129(100)$ & & \\
No & $0(0)$ & 0.018 \\
\hline $\begin{array}{l}\text { Diabetes } \\
\text { Yes } \\
\text { No }\end{array}$ & $\begin{array}{l}121(94.1) \\
8(5.9)\end{array}$ & & \\
\hline $\begin{array}{l}\text { Obesity } \\
\text { Yes } \\
\text { No }\end{array}$ & $129(100)$ & & \\
\hline $\begin{array}{l}\text { Other } \\
\text { Yes } \\
\text { No }\end{array}$ & $15(11.8)$ & \\
\hline
\end{tabular}

\section{Utilization of Mobile Phones for Healthcare Services}

According to Table 4, most of the participants (80.1\%) knew that they could call doctors through their mobile phones. Mixed responses were noted in questions related to doctor advice on diseases or treatments. Also, all participants did not answer some questions.

\section{Spending Money for Online Healthcare Services}

In this survey respondents were asked about spending money for the online healthcare services. Among them, $17 \%$ of the respondents agreed in spending on online healthcare services. However, no one responded about the amount that they were spending on healthcare services using their mobile phones.

\section{Trust of Respondents on Online Healthcare Services}

The results indicated that most of the participants (84\%) did not trust online healthcare services. Moreover, few 
Table 3 Availability and Utilization of Mobile Phones Among Respondents $(n=129)$

\begin{tabular}{|c|c|c|c|}
\hline Utilization of Mobile Phones & n (\%) & Mean Value & $P$ value \\
\hline \multicolumn{4}{|l|}{$\begin{array}{l}\text { Do you have your own mobile } \\
\text { phone? }\end{array}$} \\
\hline Yes & $128(99.0)$ & 1.01 & 0.100 \\
\hline No & I (I.0) & & \\
\hline \multicolumn{4}{|l|}{$\begin{array}{l}\text { Does any member of your } \\
\text { house own a mobile phone? }\end{array}$} \\
\hline Yes & $124(96.0)$ & 1.04 & 0.196 \\
\hline No & $5(4.0)$ & & \\
\hline \multicolumn{4}{|l|}{$\begin{array}{l}\text { How many mobile phones are } \\
\text { owned by members of your } \\
\text { house? } \\
\text { Results were not reported }\end{array}$} \\
\hline \multicolumn{4}{|l|}{$\begin{array}{l}\text { Do you share your phone with } \\
\text { others? }\end{array}$} \\
\hline Yes & $32(24.7)$ & 1.75 & 0.434 \\
\hline No & $97(75.3)$ & & \\
\hline \multicolumn{4}{|l|}{$\begin{array}{l}\text { Do you use the internet on } \\
\text { your phone? }\end{array}$} \\
\hline Yes & $128(99.0)$ & 1.01 & 0.100 \\
\hline No & I (I.0) & & \\
\hline \multicolumn{4}{|l|}{$\begin{array}{l}\text { How long have you been using } \\
\text { your own mobile phone? } \\
\text { Results were not reported }\end{array}$} \\
\hline \multicolumn{4}{|l|}{$\begin{array}{l}\text { Number of incoming calls, SMS } \\
\text { and voice messages received } \\
\text { per week related to? }\end{array}$} \\
\hline
\end{tabular}

participants (4\%) believed in the medications provided by the doctor without seeing the current situation of the patient.

\section{Discussion}

The results of this study about the readiness of Saudi citizens towards the implementation of the e-health system in Saudi Arabia revealed that the majority of the respondents owned mobile phones and used the internet on these devices. These results are in line with the high penetration rate of smartphones $(87.43 \%)$ and the internet $(88.0 \%)$ in Saudi Arabia in $2020 .^{25,26}$ It is important to note that mobile phones allow users to search for medical advice, have access to personal health information, receive the results of medical examinations, plan appointments with doctors, access the internet to obtain medical information, etc. $^{27}$ According to Khatum et al, "Ownership of mobile phones among the population and healthcare providers is the most important factor in supporting the large-scale implementation of mobile-based intervention". ${ }^{28}$ Likewise, it was detected that more than half of the participants had knowledge about the e-health system. In this sense, the high rates of ownership of mobile phones by the participants and the availability of the internet through these devices suggested that there is great potential for the establishment of e-health systems in Saudi Arabia.

On the other hand, it was observed that most of the participants did not trust or believe in online healthcare services or in online medical consultations, and did not spend money to contract healthcare services through mobile phones. Undoubtedly, these negative perceptions about these issues are barriers that affect the successful implementation of e-health systems in Saudi Arabia. ${ }^{29}$

Also, some important questions presented in Tables 3 and 4 were not answered by the respondents. Regarding Table 3, they did not answer the question "How long have you been using your own mobile phone? The answer to this question would have allowed knowing the experience of the participants to send and receive messages and to use the functionalities and applications available on the Internet. The lack of these skills represents a barrier to properly managing e-health systems. ${ }^{28}$ Regarding Table 4, the participants did not answer the important question "Why will not you ask for medical services through your mobile phone? Obviously, the answer to this question would have indicated the willingness and tendency of the participants to ask and request the availability of medical services in the e-health system through their mobile phones. Among other interpretations, the lack of interest in answering the aforementioned questions suggests that participants do not care about the implementation of the e-health system in Saudi Arabia. In this regard, the implementation of new technologies usually faces obstacles to their final acceptance by users, as is the case of e-heath technologies in some countries. ${ }^{30-32}$

In relation to these observations, it is convenient to mention that in addition to the availability of technologies, the will and motivation of people is important for the adoption of e-health systems. ${ }^{29}$ In our opinion, the lack of motivation to adopt e-health services is associated with cultural and social aspects of the Arab people. Also, another reason why the majority of the population does not have confidence or motivation to adopt e-health systems is the fact that they consider that mobile phones are a source of distraction in health institutions where healthcare workers use them during working hours to send text 
Table 4 Utilization of Mobile Phones for Healthcare Services $(n=129)$

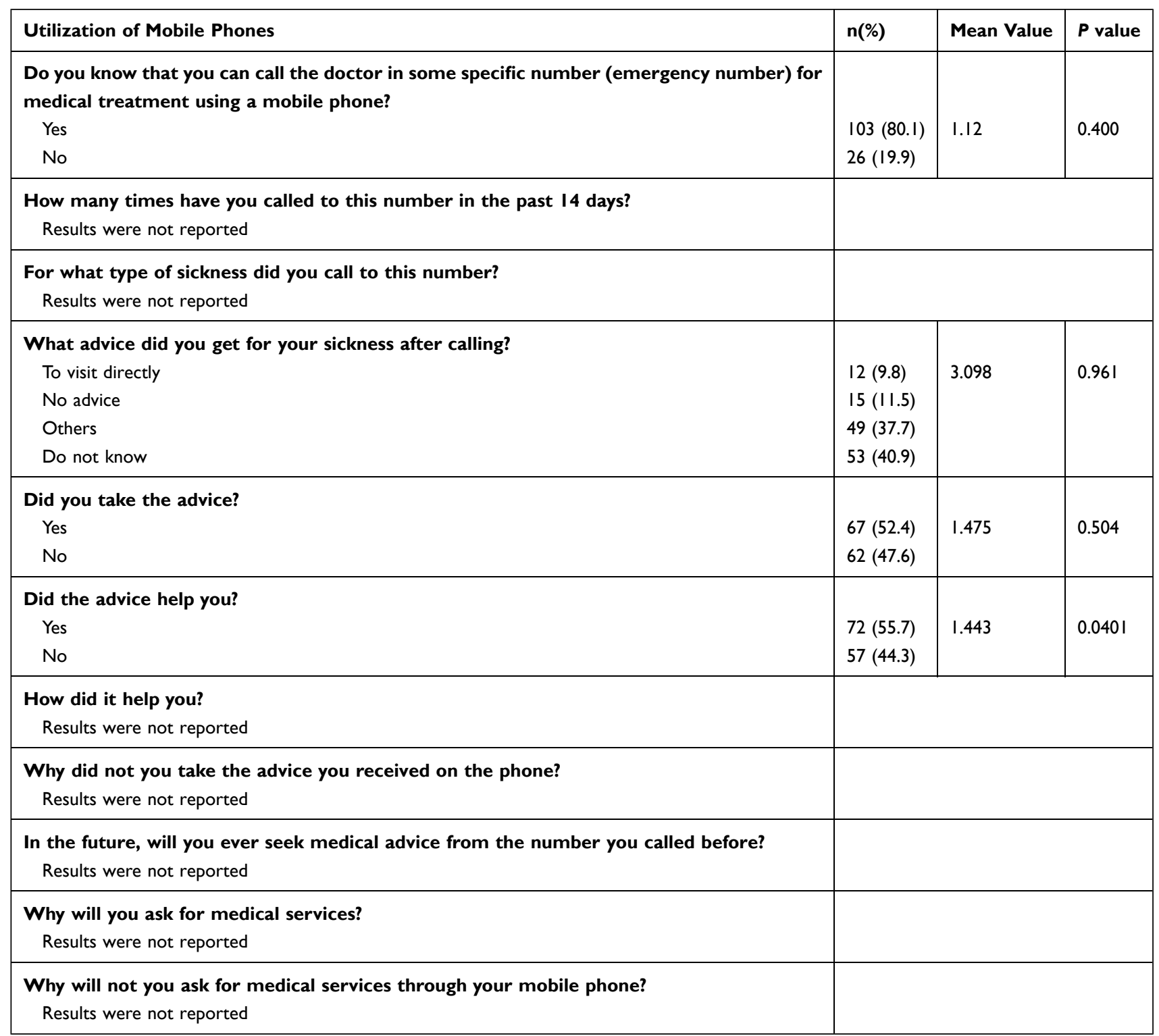

messages, read news, check social issues, surfing, shop online, and play games. ${ }^{33}$ In the same way, aspects related to the privacy of patient information, costs, and lack of technical training and supporting staff are obstacles that accentuate people's lack of trust in the e-health system. $^{34,35}$ In this sense, privacy and lack of trust are important parameters that need to be clarified in order to boost e-health readiness in Saudi Arabia.

Faced with this situation, motivational programs should be implemented to increase the awareness of the population towards the adoption of electronic health systems. $^{36-38}$ It is also necessary to point out the importance and potential of electronic health systems to manage cardiovascular diseases, diabetes, obesity, cancer, and other illnesses that afflict a large part of the Arab population. ${ }^{27,39-44}$ In the same way, measures must be implemented to ensure the confidentiality, privacy, and security of the patients' health records. In this regard, to improve data privacy it is recommended to install physical safeguards in such a way that only the authorized person with their user ID and a secure password can use the electronic applications. Also, this system must have an automatic logout after a certain time. Moreover, the app developers should do audits of the 
data and keep the audit records. In addition, the network administrator should implement procedures to prevent the exploitation of the user data. Finally, it is necessary to promote the training and education of users about the e-health system and coordinate all the participants involved in the implementation process, such as healthcare providers, patients, and the government. ${ }^{36}$

The strength of this work lies in the fact that it is the first study that reveals the opinions of a group of patients about the adoption of the e-health system in Saudi Arabia. The findings of this research might be useful in guiding the government, policymakers, e-health implementers, and healthcare providers in Saudi Arabia, and other developing countries as well, to take measures aimed at motivating patients to adopt the electronic health system.

This paper has some limitations. Firstly, the results of this study cannot be generalized to all of Saudi Arabia because the sample size was small. On the other hand, the analysis of the findings was mostly frequency presentations of the responses and no quantitative statistical analysis has been done on the results that might restrict the examination of e-health readiness. Another limitation was that no question was asked for the age category of participants. Future work should be aimed at solving the aforementioned limitations and conducting similar studies involving all regions of the Kingdom of Saudi Arabia.

\section{Conclusion}

The results of this study revealed that the majority of the respondents are reluctant to adopt the electronic e-health system promoted in the Saudi Vision 2030 strategic plan. The main factors that hinder the readiness towards the adoption of e-health are lack of confidence in online medication and lack of trust in online healthcare services. This lack of motivation can be caused by fear of privacy breaches, fear of loss of personal data and information, lack of technical support, and the mistrust in doctors who frequently use their cell phones to distract themselves during working hours. To change this behavior, it is necessary to develop awareness campaigns and strategies that suggest the importance of using the e-heath program in the Saudi Arabian healthcare system. In addition, it is necessary that the network administrator implement procedures to protect confidentiality and security of patient health records.

\section{Disclosure}

The author reports no conflicts of interest in this work.

\section{References}

1. Hoque M, Mazmum M, Bao Y. e-Health in Bangladesh: current status, challenges, and future direction. Int Technol Manag Rev. 2014;4(2):87-96. doi:10.2991/itmr.2014.4.2.3

2. Yusif S, Hafeez-Baig A, Soarb J. e-Health readiness assessment factors and measuring tools: a systematic review. Int J Med Inform. 2017;107:56. doi:10.1016/j.ijmedinf.2017.08.006

3. Eysenbach G. What is e-health? J Med Internet Res. 2001;3(2):E20. doi:10.2196/jmir.3.2.e20

4. World Health Organization. Eastern Mediterranean Region health observatory. Available from: https://www.who.int/goe/en/. Accessed April 23, 2020.

5. WHO. Global Diffusion of eHealth: Making Universal Health Coverage Achievable. Report of the Third Global Survey on eHealth. Geneva: World Health Organization; 2016.

6. Altuwaijri M. Electronic-health in Saudi Arabia. Saudi Med J. 2008;29(2):171-178.

7. Peters K, Glasser M E-health. Encyclopædia Britannica, Inc. 3013. Available from: https://www.britannica.com/science/e-health. Accessed August 13, 2020.

8. Zayyad M, Toycan M. Factors affecting sustainable adoption of e-health technology in developing countries: an exploratory survey of Nigerian hospitals from the perspective of healthcare professionals. Peer J. 2018;6:e4436. doi:10.7717/peerj.4436

9. Yaylacicegi U, Mitchell S. Differential impacts of four types of EHR implementation on small, medium, and large hospitals. Int J Electron Healthc. 2012;7(2):125-140. doi:10.1504/IJEH.2012.049874

10. Biruk S, Yilma T, Andualem M, et al. Health professionals readiness to implement electronic medical record system at three hospitals in Ethiopia: a cross sectional study. BMC Med Inform Decis Mak. 2014;14:115. doi:10.1186/s12911-014-0115-5

11. Uluc C, Ferman M. A comparative analysis of user insights for e-health development challenges in Turkey, Kingdom of Saudi Arabia, Egypt and United Arab Emirates. J Manag Market Logist. 2016;3(2):176-189.

12. Szlezak N, Evers M, Wang J, et al. The role of big data and advanced analytics in drug discovery, development, and commercialization. Clin Pharmacol Ther. 2014;95(5):492-495. doi:10.1038/clpt.2014.29

13. GDP. Available from: https://data.worldbank.org/indicator/NY.GDP. MKTP.CD?locations=SA. Accessed December 18, 2020.

14. United Nations. Available from: https://www.un.org/en/development/ desa/population/publications/pdf/trends/Population2030.pdf. Accessed December 18, 2020.

15. AlBar A, Hoque M. Patient acceptance of e-health services in Saudi Arabia: an integrative perspective. Telemed e-Health. 2019;25 (9):847-852. doi:10.1089/tmj.2018.0107

16. Almasabi M. An overview of health system in Saudi Arabia. Res J Med Sci. 2013;7:70-74.

17. Al-Shorbaji N, Househ M, Taweel A, et al. Middle East and North African Health Informatics Association (MENAHIA): building sustainable collaboration. Yearb Med Inform. 2018;27(01):286-291. doi:10.1055/s-0038-1641207

18. Almuayqil S. Integrated Framework of Knowledge Discovery and Knowledge Management for e-Health in Saudi Arabia: Supporting Citizens with Diabetes Mellitus. Staffordshire University; 2017.

19. Mantas J, Hasman A, Househ M. Enabling Health Informatics Applications. Vol. 213. IOS Press; 2015.

20. Noor A. The utilization of e-health in the Kingdom of Saudi Arabia. Int Res J Eng Technol. 2019;6:1229-1239.

21. Qurban M, Austria R Public perception on e-health services: implications of preliminary findings of KFMMC for military hospitals in KSA. Paper presented at the Proceedings of the European and Mediterranean Conference on Information Systems (EMCIS); Accessed December 18, 2020; 2008; Dubai. 
22. Khoja S, Scott R, Casebeer A, et al. e-Health readiness assessment tools for healthcare institutions in developing countries. Telemed e-Health. 2007;13(4):425-432. doi:10.1089/tmj.2006.0064

23. Lindquist A, Johansson P, Petersson G, et al. The use of the Personal Digital Assistant (PDA) among personnel and students in health care: a review. J Med Internet Res. 2008;10(4):e31. doi:10.2196/jmir.1038

24. Mosa A, Yoo I, Sheets L. A systematic review of healthcare applications for smartphones. BMC Med Inform Decis Mak. 2012;12(1):67. doi:10.1186/1472-6947-12-67

25. Smartphone penetration as share of population in Saudi Arabia 2017-2025. Available from: https:/www.statista.com/statistics/ 625436/smartphone-user-penetration-in-saudi-arabia/\#: :text= Smartphone\%20penetration\%20as\%20share\%20of\%20population\% 20in\%20Saudi\%20Arabia\%202017\%2D2025\&text=In\%202019\%2C $\% 2080.7 \% 20$ percent $\% 20$ of,Saudi\%20Arabia\%20used $\% 20 a \%$ 20smartphone. Accessed December 16, 2020.

26. Internet user penetration in Saudi Arabia from 2015 to 2025. Available from: https:/www.statista.com/statistics/484930/internetuser-reach-saudi-arabia/. Accessed December 16, 2020.

27. Hoque M. An empirical study of mHealth adoption in a developing country: the moderating effect of gender concern. BMC Med Inform Decis Mak. 2016;16:51. doi:10.1186/s12911-016-0289-0

28. Khatum F, Heywood A, Pradeep R, Hanifi S, Bhuiya A, Liaw S-T. Determinants of readiness to adopt mHealth in a rural community of Bangladesh. Int J Med Inform. 2015;84:847-856. doi:10.1016/j. ijmedinf.2015.06.008

29. Kgasi M, Kalema B. Assessment e-health readiness for rural South African Areas. J Ind Intell Info. 2014;2(2):131-135. doi:10.12720/ jiii.2.2.131-135

30. Van Velsen L, Evers M, Bara CD, et al. Understanding the acceptance of an e-health technology in the early stages of development: an end-user walkthrough approach and two case studies. JMIR Form Res. 2018;2(1):e10474. doi:10.2196/10474

31. Khan I, Xitong G, Ahmad Z, et al. Investigating factors impelling the adoption of e-health: a perspective of African expats in China. SAGE Open. 2019;1-12.

32. Hossain N, Okajima H, Kitaoka H, et al. Consumer acceptance of ehealth among rural inhabitants in developing countries (a study on portable health clinic in Bangladesh). Procedia Comput Sci. 2017;111:471-478. doi:10.1016/j.procs.2017.06.049

33. Aljohani K. Smartphone use among healthcare providers in Saudi Arabia: a cross-sectional study. Int J Sci Study. 2018;6(2).
34. Sayed M. Knowledge, attitude and behaviour of dental health care providers towards health Electronic record systems in Saudi Arabia. Health Info Libr J. 2019; 12290.

35. Adhikari R, Richards D, Scott K Security and privacy issues related to the use of mobile health apps. 25 Australasian Conference on Information Systems. New Zealand; 2014

36. Saleh S, Khodor R, Alameddine M, et al. Readiness of healthcare providers for eHealth: the case from primary healthcare centers in Lebanon. BMC Health Serv Res. 2016;16:644. doi:10.1186/s12913016-1896-2

37. Qasim A, Kharbat F, Al-Shawakbeh A, et al. Examining the factors affecting the adoption of e-health innovative technology. Int J Econ Bus Res. 2018;16:196. doi:10.1504/IJEBR.2018.10014172

38. Kho J, Gillespie N, Khan M. A systematic scoping review of change management practices used for telemedicine service implementation. BMC Health Serv Res. 2020;20:815. doi:10.1186/s12913-020-05657$\mathrm{w}$

39. Hossain M, Tasnim S, Sharma R, et al. Digital interventions for people living with non-communicable diseases in India: a systematic review of intervention studies and recommendations for future research and development. Digit Health. 2019;5:1-18. doi: $10.1177 / 2055207619896153$

40. Goruntla N, Mallela V, Devanna N. Impact of pharmacist-directed counseling and message reminder services on medication adherence and clinical outcomes in type 2 diabetes mellitus. $J$ Pharm Bioallied Sci. 2019;11:69-76. doi:10.4103/JPBS.JPBS_211_18

41. Feroz A, Kadir M, Saleem S. Health systems readiness for adopting $\mathrm{m}$-health interventions for addressing noncommunicable diseases in low- and middle-income countries: a current debate. Glob Health Action. 2018;11:1496887. doi:10.1080/16549716.2018.1496887

42. Larson J, Rosen A, Wilson F. The effect of telehealth interventions on quality of life of cancer patients: a systematic review and meta-analysis. Telemed e-Health. 2018;24:397-405. doi:10.1089/ tmj.2017.0112

43. Jin K, Khonsari S, Gallagher R, et al. Telehealth interventions for the secondary prevention of coronary heart disease: a systematic review and meta-analysis. Eur J Cardiovasc Nurs. 2019;18:260-271. doi: $10.1177 / 1474515119826510$

44. Alwashmi M, Hawboldt J, Davis E, et al. The effect of smartphone interventions on patients with chronic obstructive pulmonary disease exacerbations: a systematic review and meta-analysis. JMIR mHealth uHealth. 2016;4:e105. doi:10.2196/mhealth.5921
Journal of Multidisciplinary Healthcare

\section{Publish your work in this journal}

The Journal of Multidisciplinary Healthcare is an international, peerreviewed open-access journal that aims to represent and publish research in healthcare areas delivered by practitioners of different disciplines. This includes studies and reviews conducted by multidisciplinary teams as well as research which evaluates the results or conduct of such teams or healthcare processes in general. The journal covers a very wide range of areas and welcomes submissions from practitioners at all levels, from all over the world. The manuscript management system is completely online and includes a very quick and fair peer-review system. Visit http://www.dovepress.com/testimonials. php to read real quotes from published authors. 